\title{
Efficiency of Mentha piperita L. and Mentha pulegium L. essential oils on nutritional indices of Plodia interpunctella Hübner (Lepidoptera: Pyralidae)
}

\author{
K. Saeidi, B. Hassanpour \\ Department of Entomology, Agricultural and Natural Resources Research Center, Yasouj, Iran
}

\begin{abstract}
Antifeedant activity of plant extracts from Mentha piperita L. and Mentha pulegium L. were tested against the Indian meal moth, Plodia interpunctella (Hübner). The nutritional indices: relative growth rate (RGR), relative consumption rate (RCR), efficiency of conversion of ingested food (ECI) and feeding deterrence index (FDI) were measured for first-instar larvae (15-d old). Treatments were evaluated using a flour disk bioassay in the dark, at $25 \pm 1^{\circ} \mathrm{C}$ and $60 \pm 5 \%$ R.H. Concentrations of $0,0.1,0.5,0.75,1,1.5$ and $2 \mu \mathrm{L} /$ disk were prepared from each essential oil. After $72 \mathrm{~h}$, nutritional indices were calculated. $M$. piperita oils were more effective than $M$. pulegium oils, by significantly decreasing the RGR, RCR and FDI. At the highest concentration tested ( $2 \mu \mathrm{L} /$ disk), the ECI (9\%) was significantly reduced.
\end{abstract}

\section{Introduction}

Stored cereals, oilseeds, pulses, spices, dried fruits, tree nuts and their processed foods are important for food and trade purposes and suffer economic and quality losses due to insect pests (Lamiri et al., 2001; Passino et al., 2004; Tapondjou et al., 2005; Ali \& Rizvi, 2008). There are over 600 species of beetle pests and 70 species of moths capable of causing quantitative and qualitative losses (Rajendran, 2002). In developing countries, damage is between 10 to 40\% (Shaaya et al., 1997). In some rural areas of Iran that use traditional storages,

Correspondence: Karim Saeidi, Department of Entomology, Agricultural and Natural Resources Research Center, P.0. Box 351, Yasouj, Iran. Tel.: +98.741.3334821 / +98.741.3334821 - Fax: +98.741.3334011. E-mail: saeidi391@yahoo.com

Key words: essential oil, nutritional indices, Plodia interpunctella.

Received for publication: 3 December 2012.

Revision received: 31 July 2013.

Accepted for publication: 7 August 2013.

(C) Copyright K. Saeidi and B. Hassanpour, 2014

Licensee PAGEPress, Italy

Journal of Entomological and Acarological Research 2014; 46:715

doi:10.4081/jear.2014.715

This article is distributed under the terms of the Creative Commons Attribution Noncommercial License (by-nc 3.0) which permits any noncommercial use, distribution, and reproduction in any medium, provided the original author(s) and source are credited. damage caused by stored product insects can be as high as $80 \%$ (Modarres-Najafabadi et al., 2006).

P. interpunctella (Hübner) (Indian meal moth) is considered to be the most troublesome of the moths infesting stored products in the world (Phillips et al., 2000; Mohandass et al., 2007). It attacks all cereal products, whole grains, dried fruits, pet foods, birdseed, dried milk and nuts (Arthur et al., 1991). The larvae are generalists, as they can feed on grain products, seeds, dried fruit, dog food, and spices (Arthur et al., 1990; Mohandass et al., 2007). Damage is caused by the larvae spinning silken threads as they feed and crawl, thus webbing the particles of food together (Simmons \& Nelson, 1975). The control of this pest in storage systems mainly depends on fumigants such as methyl bromide or phosphine, and fogging with pyrethrins or dichlorvos. However, methyl bromide was banned in many countries starting in 2004, because of its ozone-depleting properties (Hansen \& Jensen, 2002).

Synthetic pesticides have been considered the most effective and accessible means of controlling insect pests of stored products (Huang $\&$ Subramanyam, 2005). These chemicals are associated with undesirable effects on the environment due to their slow biodegradation and some toxic residues in products, affecting mammalian health (Benhalima et al., 2004; Isman, 2006; Halder et al., 2010). The adverse effects of synthetic pesticides have amplified the need for an effective and biodegradable pesticide.

Natural products are an excellent alternative to synthetic pesticides as a means to reduce negative impacts on human health and the environment. Among the various kinds of natural substances that have received particular attention as natural agents for insect management are essential oils from aromatic plants. Essential oils are renewable, non-persistent in the environment and relatively safe to natural enemies, non-target organisms and human beings (Halder et al., 2010).

Essential oils are defined as any volatile oil(s) that have strong aromatic components and that give a distinctive odor, flavor or scent to a plant. These are the by-products of plant metabolism and are commonly referred to as volatile plant secondary metabolites (Koul et al., 2008). Because of the intensity of plant-insect interactions, the plants have well-developed defense mechanisms against pests and are excellent sources of new insecticidal substances. Their components and quality vary with geographical distribution, time of harvest, growing conditions and method of extraction (Yang \& Zheng, 2005). Effects of essential oils on stored-product insect pests have been reported on extensively (Ogendo et al., 2008; Park et al., 2008; Benzi et al., 2009; Ayvaz et al., 2010; Nayamador et al., 2010; Taghizadeh et al., 2010).

The insecticidal activity of some essential oils from Lamiaceae has been evaluated against a number of stored product insects. For example, Mollai et al. (2010) found strong insecticidal activity of essential oil from Satureja hortensis (Lamiaceae) on $P$. interpunctella. The 24-h $\mathrm{LC}_{50}$ values against adults were $140 \mu \mathrm{L} / \mathrm{L}$ air. In another experiment, Aliakbari et al. (2010) studied insecticidal activity of the essential oil from Thymus daenensis (Lamiaceae) on Tribolium confusum (Tenebrionidae). Mortality was evaluated after 24 and $48 \mathrm{~h} . \mathrm{LC}_{50}$ and 
$\mathrm{LC}_{95}$ values were 50 and $169 \mu \mathrm{L}$ after $24-\mathrm{h}$ and 42 and $103 \mu \mathrm{L}$ after 48 h, respectively. Ebadollahi \& Mahboubi (2011) studied fumigant activity of the essential oil from Lavandula stoechas L. (Lamiaceae) on Tribolium castaneum. Based on the results of this research, essential oils of $L$. stoechas should be considered as a potential control agent against T. castaneum. Rafiei-Karahroodi et al. (2009) studied the effect of essential oils from Dracocephalum moldavica, Lavandula officinalis, Melissa officinalis and Rosmarinus officinalis on 1-d and 3-d-old eggs of $P$. interpunctella. Results indicated that $M$. officinalis and $R$. officinalis are suitable candidates for replacing synthetic pesticides in warehouses to control $P$. interpunctella.

The main goal of the present study was to evaluate the insecticidal activities of essential oils from $M$. piperita and $M$. pulegium grown in Iran for the control of $P$. interpunctella.

\section{Materials and methods}

\section{Moth culture}

The Indian meal moths, based on described by Silhacek \& Miller (1972), were reared on artificial diet containing: cornmeal (26\%), whole wheat flour (23\%), glycerol (16\%) honey (14\%), ground dog meal (10\%), brewers' yeast (5\%), rolled oats (4\%) and wheat germ (2\%) in a chamber set to a light:dark period of (11:13) and a temperature of $28 \pm 2^{\circ} \mathrm{C}$.

\section{Collected and dried plant specimens}

Two plants known to have medicinal activity, M. piperita L. and $M$. pulegium L., were collected from their natural habitats, from different localities in Iran. The identity of each plant species was verified by En. Shahabedin Mirinejad (botanical specialist from Agriculture and Natural Resources Researches Center of Kohgiloyeh and Boyerahmad, Yasouj), using live specimens and photographs.

\section{Extraction of essential oils}

Plant materials were air dried in the shade at room temperature (26$28^{\circ} \mathrm{C}$ ) for $20 \mathrm{~d}$ and stored in darkness until distillation. The essential oils were isolated from dried plant samples by hydro-distillation using a Clevenger apparatus. Conditions of extraction were: $50 \mathrm{~g}$ of air-dried sample, 1:10 plant material/water volume ratio, $3 \mathrm{~h}$ distillation. The essential oils were collected, dried over anhydrous sodium sulfate and stored at $4^{\circ} \mathrm{C}$ until use.

\section{Flour disk bioassay}

According to the method of Mohandass et al. (2007) a suspension of $10 \mathrm{~g}$ wheat flour in $50 \mathrm{~mL}$ distilled water was prepared. A micropipette was used to transfer $200-\mu \mathrm{L}$ aliquots from the suspension onto a plastic sheet. After $4 \mathrm{~h}$ at room temperature, the wheat flour suspensions in the form of spherical disks were transferred to a petri dish. Prepared disks were kept for $12 \mathrm{~h}$ to dry inside an oven, after which the weight of the flour disks was between $35-45 \mathrm{mg}$ and their moisture content was approximately 15\%. Different concentrations of essential oils from $M$. piperita and $M$. pulegium $(0.1,0.5,0.75,1,1.5$ and $2 \mu \mathrm{L}$ in $1 \mathrm{~mL}$ of acetone) were placed on each disk separately and held for $20 \mathrm{~min}$ at room temperature to allow for evaporation of the acetone. In each petri dish, one flour disk was placed along with 10 first- instar Indian meal moth larvae and held at $25 \pm 1^{\circ} \mathrm{C}$ and $60 \pm 5 \%$ R.H. for $3 \mathrm{~d}$. At the beginning of the experiment, the weight of flour disks and larvae was measured. After $3 \mathrm{~d}$, flour disks and larvae were weighed again and the number of dead larvae noted. There were 5 replicates.

\section{Nutritional indices}

Nutritional indices were calculated according to Tripathi et al. (2002), with some modifications:

$$
\text { Relative Growth Rate }(\text { RGR })=(\text { A-B }) /(B \times \text { Day })
$$

where

A=weight of live insects (mg) on the third day/number of live insects on the third day;

$\mathrm{B}=$ original weight of insects (mg)/original number of insects.

Relative Consumption Rate $(\mathrm{RCR})=\mathrm{D} /(\mathrm{B} \times$ day $)$

\section{where}

$\mathrm{D}=$ biomass ingested (mg)/number of live insects on the third day.

Percentage efficacy of conversion of ingested food (ECI) $=$ RGR/RCR $\times 100$. The feeding deterrent activity was calculated as a feeding deterrent index (Isman, 2006):

$(\% \mathrm{FDI})=[(\mathrm{C}-\mathrm{T}) / \mathrm{C}] \times 100$

where $\mathrm{C}$ is the weight consumption of food in the control and $\mathrm{T}$ is the weight consumption food in the treatment.

\section{Data analysis}

Each of the indices was calculated using a completely randomized factorial design, and five replicates were performed. The first factor in this design included three treatments, consisting of the essential oils of $M$. piperita, M. pulegium and a control, and the second factor consisted of six concentrations of plant essential oils: $0.1,0.5,0.75,1,1.5$ and $2 \mu \mathrm{L} /$ disk, and a control treatment. Before statistical analysis, the ECI and FDI nutritional indices data were normalized using an Arcsin $\sqrt{ } \mathrm{X} / 100$ transformation. The means were separated using Duncan's multiple range test at the $5 \%$ significance level.

\section{Results}

Plant source and dose significantly affected all nutritional indices (Table 1). For RCR, ECI and FDI there was a significant interaction

Table 1. Analysis of variance of essential oils of Mentha piperita and Mentha pulegium on nutritional indices of larvae of Plodia interpunctella.

\begin{tabular}{|c|c|c|c|c|c|}
\hline \multirow[t]{2}{*}{ Source of variation } & \multirow[t]{2}{*}{ Degrees of freedom } & \multicolumn{4}{|c|}{ Mean squares } \\
\hline & & RGR & $\mathrm{RCR}$ & ECI & FDI \\
\hline Plant & 1 & $7.01 \times 10^{-4^{*}}$ & $0.066^{* *}$ & $99.836^{* *}$ & $5167.934^{* *}$ \\
\hline Concentration & 6 & $0.002^{* *}$ & $0.032^{* *}$ & $26.125^{* *}$ & $1998.654^{* *}$ \\
\hline Plant×Concentration & 6 & $3.086 \times 10^{-5 n s}$ & $0.003^{* *}$ & $16.822^{* *}$ & $176.234^{* *}$ \\
\hline Error & 42 & $2.620 \times 10^{-5}$ & 3.736 & 4.354 & 0.023 \\
\hline
\end{tabular}

RGR, relative growth rate; RCR, relative consumption rate; ECI, efficiency of conversion of ingested food; FDI, feeding deterrence index; ns, non-significant; *, ** respectively significant differences at 5 and $1 \%$ level. 
Table 2. Effect of essential oils of Mentha piperita and Mentha pulegium on nutritional indices of larvae of Plodia interpunctella.

\begin{tabular}{lcccc}
\hline Essential oil & RGR $(\mathrm{mg} / \mathrm{mg} / \mathrm{day})$ & RCR $(\mathrm{mg} / \mathrm{mg} / \mathrm{day})$ & FCI $\%$ & \\
Mentha piperita & $0.026 \pm 0.002^{\mathrm{b}}$ & $0.219 \pm 0.160^{\mathrm{b}}$ & $11.94 \pm 0.76^{\mathrm{a}}$ & $34.9 \pm 3.8^{\mathrm{a}}$ \\
Mentha pulegium & $0.028 \pm 0.001^{\mathrm{a}}$ & $0.294 \pm 0.006^{\mathrm{a}}$ & $9.64 \pm 0.44^{\mathrm{b}}$ & $14.2 \pm 2.2^{\mathrm{b}}$ \\
\hline
\end{tabular}

RGR, relative growth rate; RCR, relative consumption rate; ECI, efficiency of conversion of ingested food; FDI, feeding deterrence index. a,bValues in the same column followed by different letters are significantly different $(\mathrm{P}<0.01$, Duncan's multiple range test).

Table 3. Total average effect of essential oils of Mentha piperita and Mentha pulegium at various concentrations on nutritional indices of larvae of Plodia interpunctella.

\begin{tabular}{|c|c|c|c|c|}
\hline \multirow{2}{*}{ Concentration ( $\mu \mathrm{L} / \mathrm{disk})$} & \multicolumn{4}{|c|}{ Standard error \pm average nutritional indices } \\
\hline & RGR (mg/mg/day) & RCR (mg/mg/day) & ECI $\%$ & FDI $\%$ \\
\hline 0.00 (Control) & $0.051 \pm 0.001^{\mathrm{a}}$ & $0.3131 \pm 0.015^{\mathrm{a}}$ & $16.288 \pm 0.453^{\mathrm{a}}$ & - \\
\hline 0.1 & $0.035 \pm 0.001^{\mathrm{b}}$ & $0.253 \pm 0.014^{b}$ & $13.833 \pm 0.765^{\mathrm{a}}$ & $13.281 \pm 2.050^{f}$ \\
\hline 0.5 & $0.031 \pm 0.001^{\mathrm{bc}}$ & $0.230 \pm 0.017^{c}$ & $13.478 \pm 0.749^{\mathrm{ab}}$ & $20.098 \pm 2.710^{\mathrm{e}}$ \\
\hline 0.75 & $0.027 \pm 0.000^{c}$ & $0.210 \pm 0.015^{\mathrm{d}}$ & $12.857 \pm 0.512^{\mathrm{abc}}$ & $25.889 \pm 3.112^{\mathrm{d}}$ \\
\hline 1 & $0.019 \pm 0.002^{\mathrm{d}}$ & $0.169 \pm 0.016 \mathrm{e}$ & $11.242 \pm 0.765^{\mathrm{abc}}$ & $32.705 \pm 3.256^{c}$ \\
\hline 1.5 & $0.016 \pm 0.001^{\mathrm{d}}$ & $0.116 \pm 0.023^{f}$ & $13.793 \pm 1.682^{\mathrm{cb}}$ & $48.949 \pm 6.014^{b}$ \\
\hline 2 & $0.010 \pm 0.003^{\mathrm{e}}$ & $0.102 \pm 0.039 g$ & $9.384 \pm 1.812^{\mathrm{c}}$ & $52.829 \pm 5.235^{\mathrm{a}}$ \\
\hline
\end{tabular}

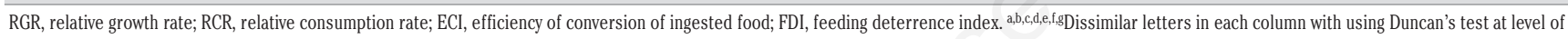
$1 \%$ together have significant differences.
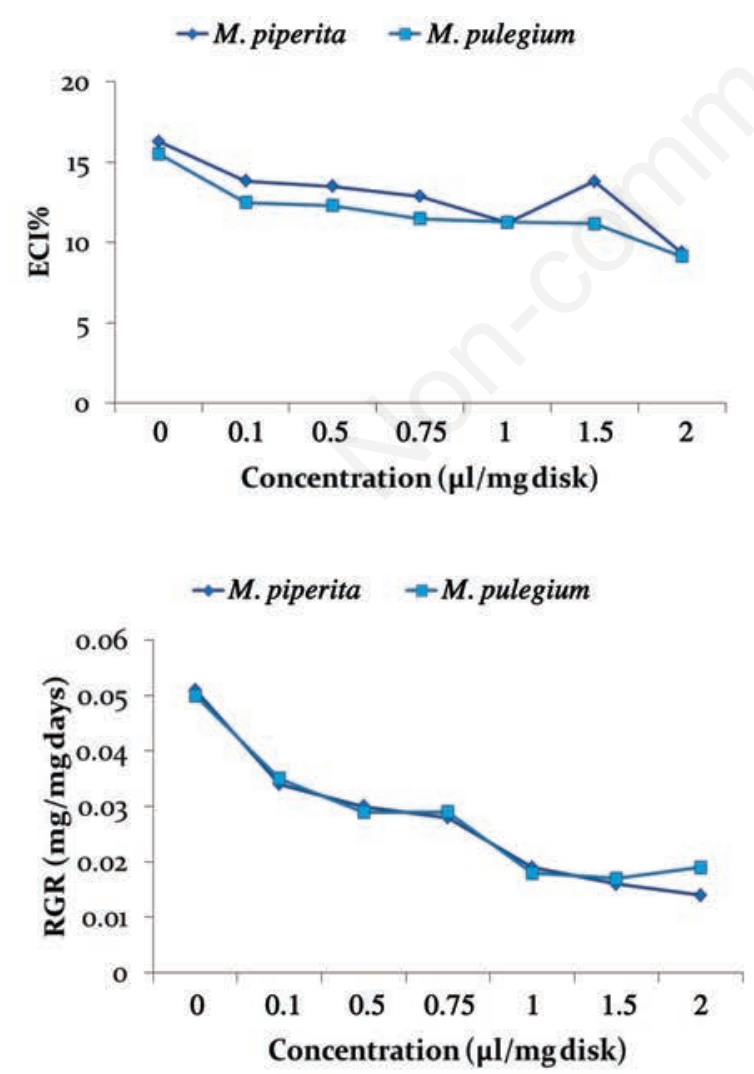
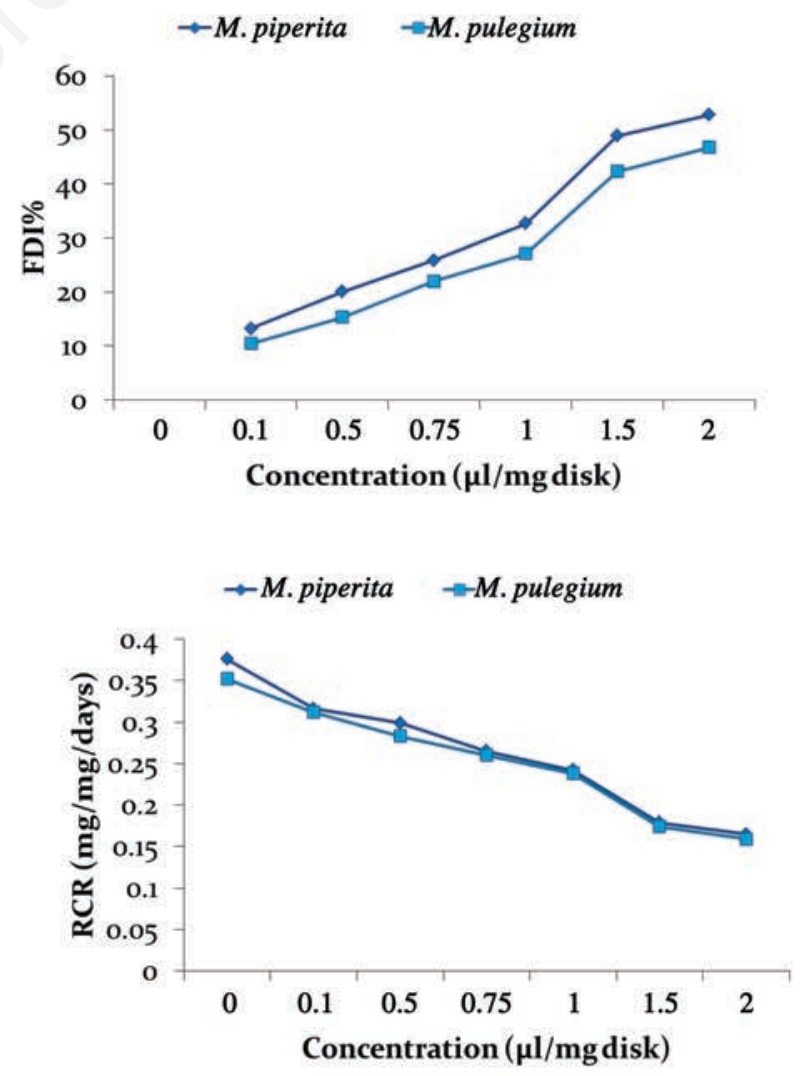

Figure 1. Effect of essential oil Mentha piperita and Mentha pulegium at various concentrations on nutritional indices larvae of Plodia interpunctella. 
between plant source and dose, indicating that the effect of plant source varied significantly with dose (Table 1). Essential oils of $M$. piperita had a significantly greater negative impact on nutritional indices than did the essential oils of M. pulegium (Tables 2 and 3). However, these differences were small (Figure 1).

\section{Discussion and conclusions}

In this study, to compare the anti-nutritional effects of essential oils of $M$. piperita and $M$. pulegium, parameters as indicators of nutrition were used by employing no-choice tests of the insects' food, which had been impregnated with various concentrations of the essential oils. In these experiments, two primary outcomes were measured. The first was weight loss of the insects compared with the control during the duration of this experiment, expressed as the RGR index. Second, the RCR index was measured and compared with control insects to measure whether test insects had taken less or avoided eating treated food. The effective weight loss could be related to the impact of essential oils on insect food (Koul et al., 2008), and to clarify avoidance of insect feeding, FDI was used. In this experiment, it was observed that increasing the concentration and changing the type of essential oil reduced the RGR and RCR values, so that there was a greater effect with essential oil at high concentrations, and regarding essential oil type, $M$. piperita was found to be more effective. In terms of the mechanism of action in response to this decrease, it is clear that low concentrations of essential oils of $M$. piperita and $M$. pulegium did not show significant differences in terms of ECI, but with very high essential oil concentrations, the value of the ECI was reduced. Even at lower concentrations of the essential oils of $M$. piperita and $M$. pulegium, there was significant inhibition of insect feeding. Therefore, the impact on the RGR and RCR can be attributed to the effects of feeding deterrence or FDI. Even at lower concentrations, these essential oils can effectively reduce insect feeding, as noted in the studies of other researchers.

In this study, to examine the anti-nutritional properties of mint essential oils, Indian meal moth was used as a model, and showed that sub-lethal concentrations of essential oils in warehouse use could prevent the insects from feeding on the stored product. Therefore, we would conclude that a method to combine these essential oils with some storage products could be effective in controlling pests.

\section{References}

ALI A., RIZVI P.0., 2008. - Bio-efficacy of some plant leaf extracts against mustard aphid, Lipaphis erysimikalt on Indian mustard, Brassica juncea. - J. Plant. Protec. Res. 50: 2.

ALIAKBARI J., FALLAHZADEH M., GHASEMI A., ABDIZADEH R., 2010. Insecticidal activity of essential oil from Thymus daenensis Celak against Tribolium confusum Dur. Proc. 19th Iranian Plant Protection Congress, July 31-August 3, 2010. - Iranian Research Institute of Plant Protection, Tehran, Iran.

ARTHUR F.H., HIGHLAND H.A., MULLEN M.A., 1991. - Efficiency and longevity of two commercial sex pheromone lures for Indian meal moth and almond moth (Lepidoptera: Pyralidae). - J. Econ. Entomol. 26: 64-68.

ARTHUR F.H., SIMONAITIS R.A., THRONE J.E., ZEHNER J.M., 1990. Evaluation of chlorpyrifos-methyl and chlorpyriphos-methyl plus methoprene as protectants of stored corn: small bin tests. - J. Econ. Entomol. 83: 1114-1121.

AYVAZ A., SAGDIC 0., KARABORKLUS., OZTURK I., 2010. - Insecticidal activity of the essential oils from different plants against three stored-product insects. - J. Ins. Sci. 10: 21.1-21.13.

BENHALIMA H., CHAUDHRY M.Q., MILLS K.A., PRICE N.R., 2004. Phosphine resistance in stored-product insects collected from various grain storage facilities in Morocco. - J. Stored Prod. Res. 40: 241-249.

BENZI V., STEFANAZZI N., FERRERO A., 2009. - Biological activity of essential oils from leaves and fruits of pepper tree (Schinus molle L.) to control rice weevil (Sitophilus oryzae L.). - Chilean J. Agri. Sci. 69: 154-159.

EBADOLLAHI A., MAHBOUBI M., 2011. - Insecticidal activity of essential oil isolated from Azilia eryngioides (Pau) Hedge Et Lamond against two beetle pests. - Chilean J. Agri. Res. 71: 406-411.

HALDER J., SRIVASTAVA C., DUREJA P., 2010. - Effect of methanolic extracts of periwinkle (Vinca rosea) and bottlebrush (Callistemon lanceolatus) alone and their mixtures against neonate larvae of gram pod borer (Helicoverpa armigera). - Indian J. Agri. Sci. 80: 820-823.

HANSEN L.S., JENSEN K.M.W., 2002. - Effect of temperature on parasitism and host-feeding of Trichogramma turkestanica (Hymenoptera: Trichogrammatidae) on Ephestia kuhniella (Lepidoptera: Pyralidae). - J. Econ. Entomol. 95: 50-56.

HUANG F., SUBRAMANYAM B., 2005. - Management of five stored-product insects in wheat with pirimiphosmethyl and pirimiphos-methyl plus synergized pyrethrins. - Pest Manag. Sci. 61: 356-362.

ISMAN M.B., 2006. - Botanical insecticide deterrents in modern agriculture and increasingly regulated world. - Annu. Rev. Entomol. 5: 45-66.

KOUL P., WALLA S., DHALIWAL G.S., 2008. - Essential oils as green pesticides. Potential and constraints. Biopestic. Int. 4: 63-83.

LAMIRI A., LHALOUI S., BENJILALI B., BERRADA M., 2001. - Insecticidal effects of essential oils against Hessian fly, Mayetiola destructor (Say). - Field Crop Res. 71: 9-15.

MODARRES-NAJAFABADI S.S., FANI H.R., GHOLAMIAN G.H., 2006. Study on eucalyptus product uses (seed and leaf powder) on stored product pests of wheat and barley in Sistan region-Iran. - Iran. J. Med. Aromat. Plant. 22: 117-127.

MOHANDASS S., ARTHUR F.H., ZHU K.Y., THRONE J.E., 2007. - Biology and management of Plodia interpunctella (Lepidoptera: Pyralidae) in stored products. - J. Stored Prod. Res. 43: 302-311.

MOLLAI M., IZADI H., DASHTI H., AZIZI M., RAHIMI H., 2010. Fumigant toxicity of essential oils from Satureja hortensis and Zingiber officinalis on Plodia interpunctella. Proc. 19th Iranian Plant Protection Congress, July 31-August 3, 2010. - Iranian Research Institute of Plant Protection, Tehran, Iran.

NAYAMADOR W.S., KETOH G.K., AMEVOIN K., NUTO Y., KOUMAGLO H.K., GLITHO I.A., 2010. - Variation in the susceptibility of two Callosobruchus species to essential oils. - J. Stored Prod. Res. 46: 48-51.

OGENDO J.O., KOSTYUKOVSKY M., RAVID U., MATASYOH J.C., DENG A.L., OMOLO E.O., KARIUKI S.T., SHAAYA E., 2008. - Bioactivity of Ocimum gratissimum L. oil and two of its constituents against five insects attacking stored food products. - J. Stored Prod. Res. 44: 328-334.

PARK I.K., KIM J.N., LEE Y.S., LEE S.G., YOUNG J., AHN, Y.A., SHIN S.C., 2008. -Toxicity of plant essential oils and their components against Lycoriella ingenua (Diptera: Sciaridae). - J. Econ. Entomol. 101: 139-144.

PASSINO G.S., BAZZONI E., MORETTI M., 2004. - Microencapsulation essential oils active against Indian meal moth. - Bol. Sanidad Vegetal Plagas 30: 123-130.

PHILLIPS T.W., BERBERT R.C., CUPERUS G.W., 2000. - Post-harvest integrated pest management. In: FRANCIS, F.J. (Ed.), Encyclopedia of food science and technology. 2nd ed. - Wiley Inc., New York: 2690-2701.

RAFIEI-KARAHROODI Z., MOHARAMIPOUR S., FARAZMAND H., 
KARIMZADEH-ESFAHANI J., 2009. - Effect of eighteen plant essential oils on nutritional indices of larvae Plodia interpunctella Hubner (Lepidoptera: Pyralidae). - J. Entomol. Res. 1: 209-219.

RAJENDRAN S., 2002. - Postharvest pest losses. In: Pimentel, D. (Ed.), Encyclopedia of pest management. - Marcel Dekker, Inc., New York: 654-656.

SHAAYA E., KOSTJUKOVSKI M., EILBERG J., SUKPRAKARN C., 1997. Plant oils as fumigants and contact insecticides for the control of stored-product insects. - J. Stored Prod. Res. 33: 7-15.

SILHACEK D.L., MILLER G.L., 1972. - Growth and development of the Indian meal moth, Plodia interpunctella Hubner (Lepidoptera: Pyralidae) under laboratory mass-rearing conditions. - Ann. Entomol. Soc. Am. 65: 1084-1087.

SIMMONS P., NELSON H.D., 1975. - Insects on dried fruits. USDA
Agricultural Handbook no. 464. - USDA, Washington DC, USA. TAGHIZADEH V., SAROUKOLAHI A., MOHARRAMIPOUR S., MESHKATALSADAT M.H., 2010. - Insecticidal properties of Thymus persicus essential oil against Tribolium castaneum and Sitophilus oryzae. - J. Pest. Sci. 83:3-8.

TAPONDJOU AL., ADLERB C., FONTEM DA, BOUDAA H., REICHMUTHB C., 2005. - Bioactivity of cymol and essential oils of Cupressus sempervirens and Eucalyptus saligna against Sitophilus zeamais and Tribolium confusum. - J. Stored Products Res. 41: 91-102.

TRIPATHI A.K., PRAJAPATI V., AGGARWAL K.K., KUMAR S., 2002. Bioactivity of I-carvone, d-carvone and dihydrocarvone towards three stored product beetles. - J. Econ. Entomol. 96: 1594-1607.

YANG P.Y., ZHENG S., 2005. - Adulticidal activity of five essential oils against Culex pipiens quinquetasciatus. - J. Pestic. Sci. 30: 84-89. 